\title{
La ocupación Inca en el valle del Cunas (Junín, Perú): una aproximación desde el sitio arqueológico de Arhuaturo
}

\author{
Manuel F. Perales Munguía*
}

Resumen Presentamos un asentamiento prehispánico tardío denominado Arhuaturo, localizado en la sección inferior de la cuenca del río Cunas, en la parte sur del valle del Mantaro, sierra central del Perú. Luego de revisar la información etnohistórica correspondiente y las evidencias arqueológicas presentes en el sitio, pasamos a discutir su ubicación cronológica y la naturaleza de sus ocupaciones durante el Intermedio Tardío y Horizonte Tardío, enfatizando el rol que habría desempeñado su población y la élite local en el proceso de conquista y anexión de esta zona al Tahuantinsuyu.

Palabras clave Andes Centrales, valle del Cunas, conquista Inca, elite local, competencia faccional.

\begin{abstract}
We describe a late prehispanic settlement called Arhuaturo which is located in the lower Cunas drainage in the southern part of the main Mantaro valley, in the central highlands of Peru. After a review of the relevant ethnohistorical information on the study area and the archaeological evidence from the site, we discuss its chronological position and the nature of the Late Intermediate Period and Late Horizon period occupations. We focus on the role of the settlement's population, especially the elites, in the process of Inca conquest and the consolidation of the state power in the region.
\end{abstract}

Keywords Central Andes, Cunas valley, Inca conquest, local elite, factional competition.

\footnotetext{
* Universidad Nacional Mayor de San Marcos, Lima; Director del Museo Arqueológico "Julio Espejo Núñez" de Jauja. Correo electrónico: huacrash@yahoo.com
} 
Tradicionalmente la conquista del valle del Mantaro por parte del estado Inca es considerada como un evento sumamente épico, donde se presenta a un "reino" Huanca unificado políticamente bajo la figura de un "rey" residente en Tunanmarca y que se enfrentó bélicamente a las tropas incaicas sucumbiendo de modo heroico ante ellas (Espinoza 1971, 1973). Esto se debería reflejar arqueológicamente en asentamientos locales destruidos y abandonados casi en su totalidad a inicios del Horizonte Tardío. Sin embargo, los diferentes trabajos arqueológicos sistemáticos iniciados desde la década de 1960 (vg. Browman 1970; D'Altroy 1981, 1992; Earle et al. 1987) en la región nos ofrecen datos que de forma contundente contradicen esta versión tradicional.

Durante el Intermedio Tardío en toda la región se generalizó un ambiente de profundo fraccionamiento político (D'Altroy 1994) en donde cada comunidad era liderada por un sinchi o "indio valiente" (Vega 1881 [1582]) que competía con otros similares por prestigio y status. Con la conquista Inca varios de estos jefes o señores locales se adhirieron al nuevo régimen con la intención de ganar mayor poder sobre los demás. Destacó sobre éstos el linaje de los Apoalaya, originario de la zona de Sapallanga al sur de Huancayo y con el tiempo logró coronarse como el de mayor rango en toda la antigua parcialidad de Hananhuanca (Castro 1992), la cual por su parte abarcaba la porción meridional de la denominada Huanca Huamani, la provincia Inca que comprendía el territorio ocupado por los grupos étnicos Xauxa y Huanca (Espinoza 1971).
La documentación etnohistórica (Dunbar Temple 1942; Espinoza 1973) sugiere que el éxito logrado por los Apoalaya en su carrera política se debió en gran medida a su temprana incorporación a la esfera estatal del Tahuantinsuyu, hecho que estaría siendo corroborado por ciertas evidencias arqueológicas como las que presentamos en esta ocasión y que proceden del sitio de Arhuaturo ${ }^{1}$, un asentamiento prehispánico tardío localizado a $12 \mathrm{~km}$ al oeste de la ciudad de Huancayo, en la margen derecha del valle bajo del río Cunas, el principal afluente del río Mantaro por su margen occidental en esta sección de su curso superior (Figura 1).

El sitio se emplaza a lolargo de una colina alargada de $3 \mathrm{~km}$ de largo que cuenta con pendientes moderadas y sustrato geológico de origen sedimentario detrítico (Rodríguez 1996). Las coordenadas UTM de su punto central son 463550E y $8666300 \mathrm{~N}$, estando su cima a una altitud promedio de $3.450 \mathrm{msnm}$. Desde el punto de vista ecológico se encuentra en el piso quechua (Pulgar 1967), dentro de la zona de vida denominada Estepaobosquesecomontanobajo (Tosi 1960).

\section{Antecedentes}

La cuenca del río Cunas ha recibido hasta el momento poca atención por parte de los especialistas, a excepción de Luis Hurtado de Mendoza y su equipo, que en la década de 1970 abordaron el estudio de las poblaciones precerámicas que se asentaron en esa región (Hurtado de Mendoza 1982). . Luego de reconocimientos sistemáticos y de excavaciones restringidas en dos sitios postularon que las primeras ocupaciones humanas

${ }^{1}$ Los actuales lugareños traducen Arhuaturo como "hueso quemado" o "hueso amarillo". Sin embargo, de acuerdo a la lingüística su significado original sería "barro amarillo" pues el topónimo estaría compuesto por las voces qarwa, "amarillo", y turo o turco, "barro", palabras que en el quechua Huanca se pronunciarían como alwa y tulu debido al cambio fonológico */q/ > ? y al lambdacismo */r/ > l (R. CerrónPalomino, comunic. pers. 1997). Como veremos más adelante, la existencia del término Carvaturco en un documento del siglo XVII (Espinoza 1973) confirmaría la propuesta de Cerrón-Palomino.

${ }^{2}$ Uno de los sitios excavados fue el denominado Abrigo Rocoso No. 1 de Harry Tschopik que fuera intervenido en 1959 por Rosa Fung, quien no llegó a precisar su antigüedad (Fung 1959). Actualmente varios autores cuestionan la existencia de un componente precerámico en este sitio por falta de evidencias más contundentes (vg. Kaulicke 1994). 


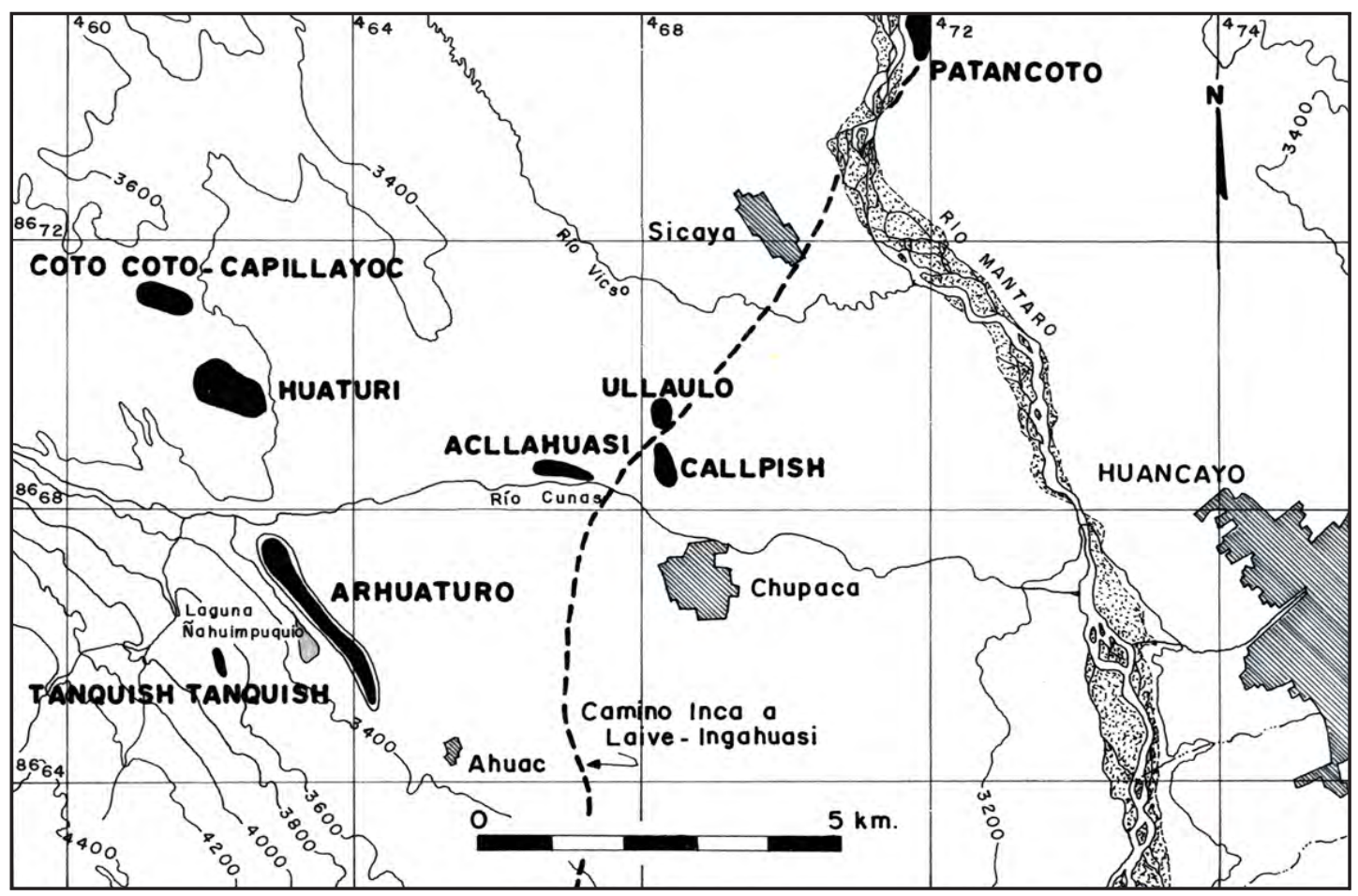

Figura 1. Ubicación del asentamiento de Arhuaturo y de otros sitios con evidencias de arquitectura Inca en el bajo Cunas.

debían remontarse por lo menos hasta el año 7000 a.C. (Hurtado de Mendoza y Chahud 1982). No obstante el valor de estas contribuciones, los aspectos relacionados a las posteriores poblaciones, particularmente aquéllas de los períodos tardíos, permanecieron casi desconocidos.

Atención especial merece al respecto el trabajo de David Browman ejecutado a fines de la década de 1960 que consistió en un reconocimiento intensivo en las terrazas aluviales que forman el piso del valle del Mantaro entre las ciudades de Jauja y Huancayo, además de laderas montañosas y algunas colinas adyacentes, con la finalidad de establecer una propuesta sobre la historia cultural prehispánica de la zona (Browman incluyó a una buena porción de la sección inferior del valle del Cunas, desde las inmediaciones del actual pueblo de Huarisca Grande hasta la desembocadura del río Cunas en el Mantaro, llegando a registrar una determinada cantidad de asentamientos del período Intermedio Tardío (Figura 2), varios de ellos reocupados durante el Horizonte Tardío (Figura 3), entre los que figuran los sitios PJuM 639, PJuM 640, PJuM 641, PJuM 642, PJuM 643, PJuM 644 y PJuM 645 (Browman 1970), que en realidad no son más que diferentes sectores del complejo arqueológico conocido como Arhuaturo y sobre los cuales Browman no otorga mayores detalles, salvo su tentativa ubicación cronológica a partir de colecciones de materiales de superficie. ${ }^{3}$

\footnotetext{
${ }^{3}$ Para mayores detalles sobre la metodología empleada por Browman así como sus criterios para la definición de sitios véase su tesis doctoral (Browman 1970). En el sistema de registro de este investigador tenemos las siguientes equivalencias: $\mathrm{P}=$ Perú, Ju=Junín, $\mathrm{M}=$ Mantaro. A continuación se agrega el número asignado a cada sitio.
} 
En años recientes y gracias a un esfuerzo coordinado entre el Instituto Nacional de Cultura de Junín y las municipalidades de Ahuac y Chupaca, se logró culminar el levantamiento topográfico de toda la zona arqueológica de Arhuaturo, trabajo que a su vez sirvió de base para el presente estudio.

\section{Aproximación etnohistórica}

De acuerdo a las fuentes escritas disponibles (Cieza 1946 [1553]; Estete 1946 [1533]; Xerez 1968 [1533]) después de la conquista Inca el valle del Mantaro y sus territorios aledaños fueron divididos en tres secciones transversales o parcialidades, Hatun Xauxa, Lurinhuanca y Hananhuanca, cada una de ellas regentada por un curaca principal (Espinoza 1971, 1973). Según esta nueva demarcación política y administrativa gran parte de la cuenca del río Cunas quedó dentro de la parcialidad de Hananhuanca (Castro 1992) cuya cabecera, originalmente instalada durante la época Inca en Sapallanga y luego en Sicaya, pasó al pueblo de San Juan Bautista de Chupaca hacia la segunda mitad del siglo XVI (Vega 1881 [1582]). ${ }^{4}$

Entre la población local reducida por los españoles en el pueblo de Chupaca se encontraba el aíllo Carvaturco [sic], delcual se cuenta con un

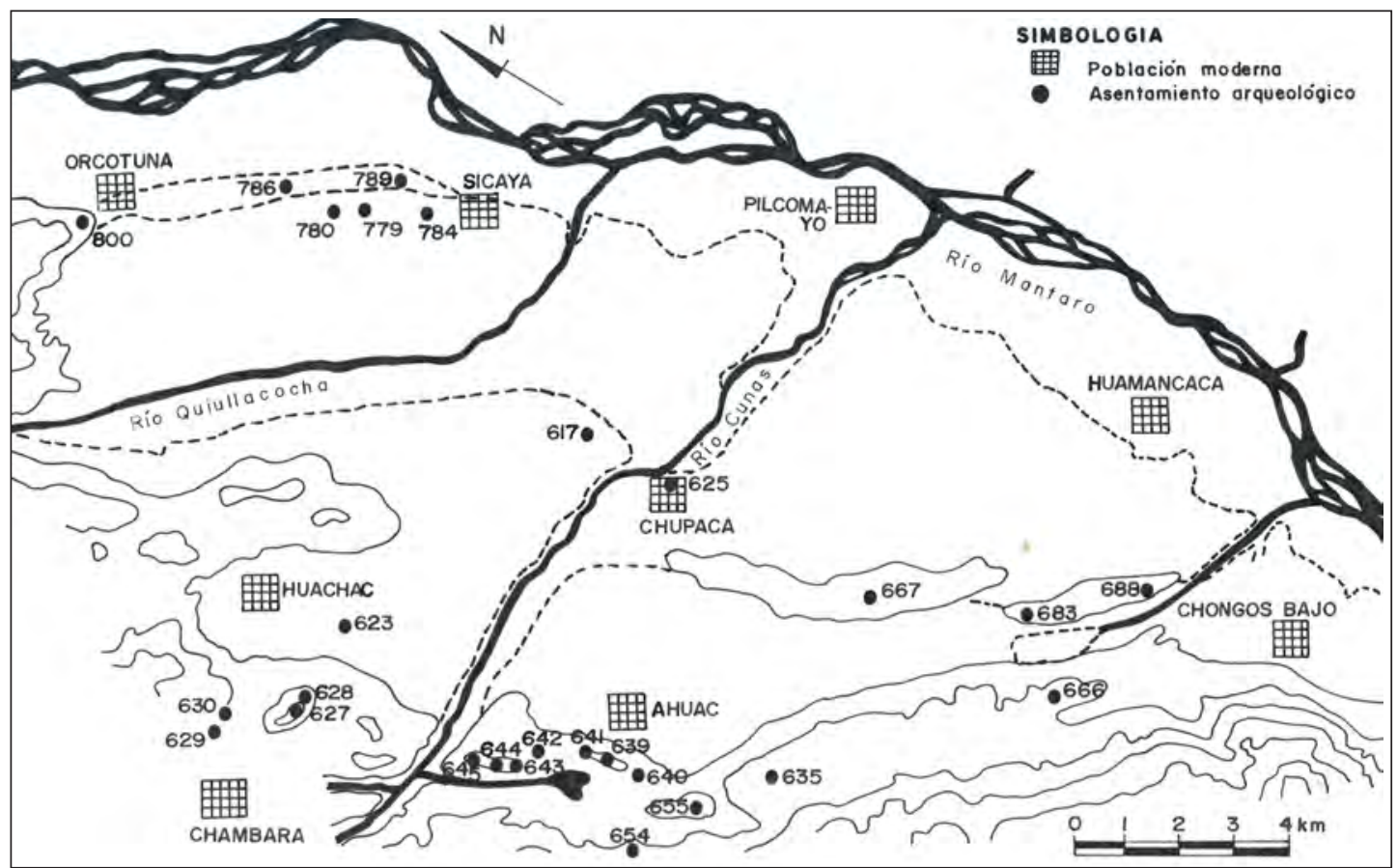

Figura 2. Sitios del periodo Intermedio Tardío (fases Matapuquio y Arhuaturo) registrados por Browman (1970) en el bajo Cunas.

${ }^{4}$ El pueblo de San Juan Bautista de Chupaca, formado como reducción de indígenas en la década de 1570 y posiblemente sobre una doctrina preexistente (Castro 1992), contaba con un mejor abastecimiento de agua, lo cual motivó al entonces curaca de Hananhuanca, Cristóbal de Apoalaya, a trasladar hacia allí su residencia, abandonando de este modo el pueblo de Santo Domingo de Sicaya (Dunbar Temple 1942; Vega 1881 [1582]). Creemos, sin embargo, que estos cambios en la localización de la sede de la cabecera de la parcialidad de Hananhuanca desde antes de la llegada de los españoles pueden constituir indicios de transformaciones en las relaciones de poder político a nivel local bajo la esfera del dominio Inca. 


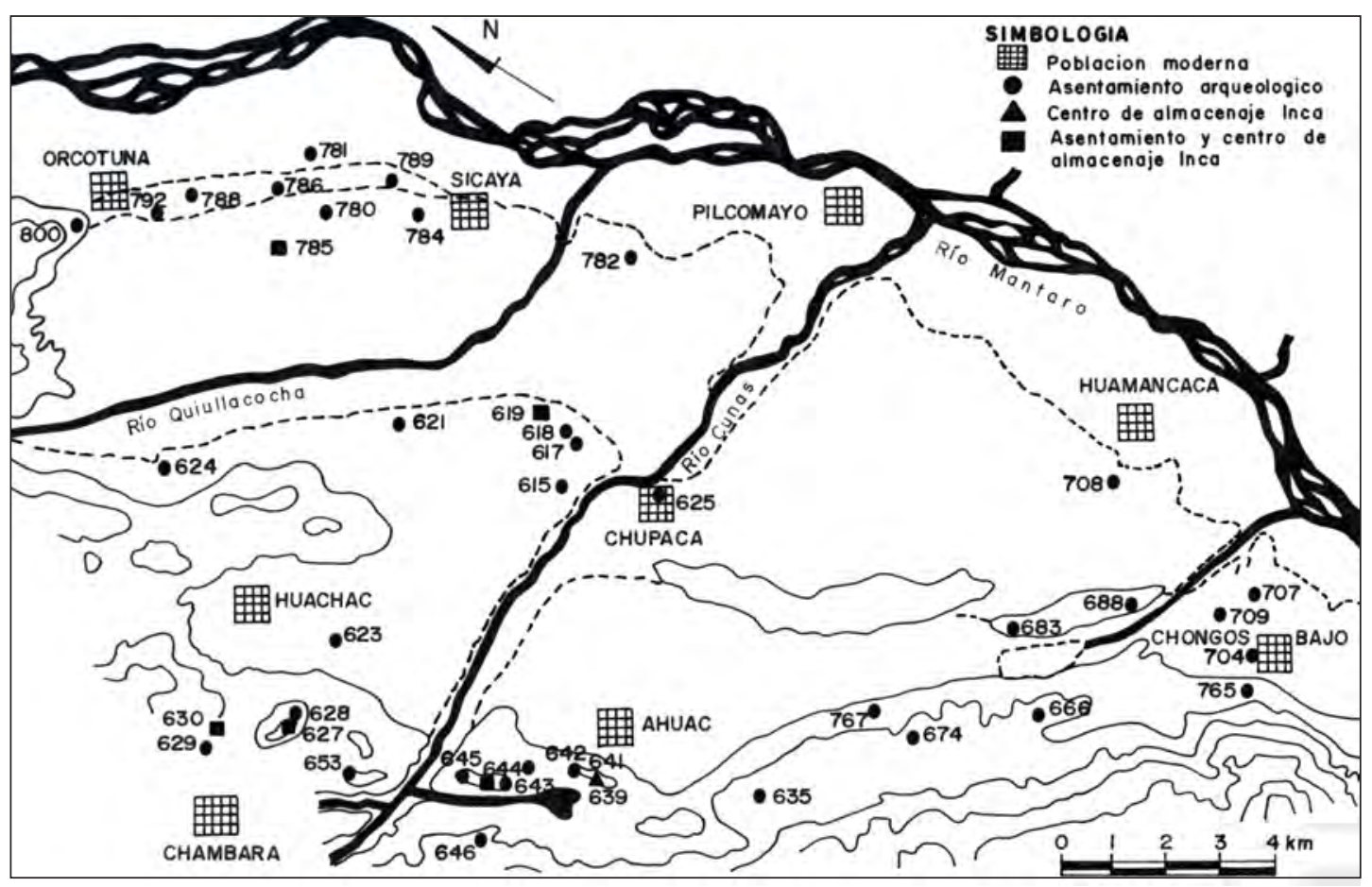

Figura 3. Sitios del período Horizonte Tardío (fase Arhuaturo-Inca) registrados por Browman (1970) en el bajo Cunas.

padrón redactado en el siglo XVII donde se menciona a don Diego Alaca como su curaca principal quien, debido a su avanzada edad, había sido sucedido por don Jerónimo Alaca, su hijo legítimo. ${ }^{5} \mathrm{Al}$ parecer estos curacas tuvieron vínculos de parentesco con los Alaya o Apoalaya de Sapallanga, el linaje de mayor poder y rango en toda la parcialidad de Hananhuanca pues en su genealogía elaborada por Dunbar Temple (1942) don Diego Alaca figura como hijo natural de Macho Apoalaya, quien a su vez fue curaca principal de Hananhuanca a inicios del sigloXVI.

En el siglo XVII la agricultura y ganadería en el valle del Mantaro cobraron mayor importancia debido a su alta rentabilidad a raíz del crecimiento de la producción minera en Huancavelica y Pasco, el crecimiento de ciudades como Jauja, Tarma y Ayacucho, y el descenso de la producción agrícola de la costa central (Samaniego 1980). En este contexto los principales curacas de la zona, propietarios de grandes extensiones de tierras agrícolas y haciendas ganaderas, pasaron a convertirse en una especie de señores feudales que además concentraban en sus manos el poder político. ${ }^{6} \mathrm{En}$ el caso de los Apoalaya ello específicamente ocurrió entre fines del siglo XVII e inicios del XVIII cuando, mediante vínculos establecidos por matrimonio, llegaron a detentar los curacazgos de

\footnotetext{
${ }^{5}$ En este documento se señala que don Diego Alaca era curaca de pachaca. Las primeras referencias sobre esta fuente escrita fueron hechas por Espinoza (1973) y una transcripción nos fue proporcionada gentilmente por Juan Mogrovejo.

${ }^{6}$ Este proceso ha sido tratado en mayor detalle por Samaniego (1980). Otros investigadores han puesto énfasis además en el control que tenían los curacas principales del valle del Mantaro sobre la producción textil local (Hurtado 2000).
} 


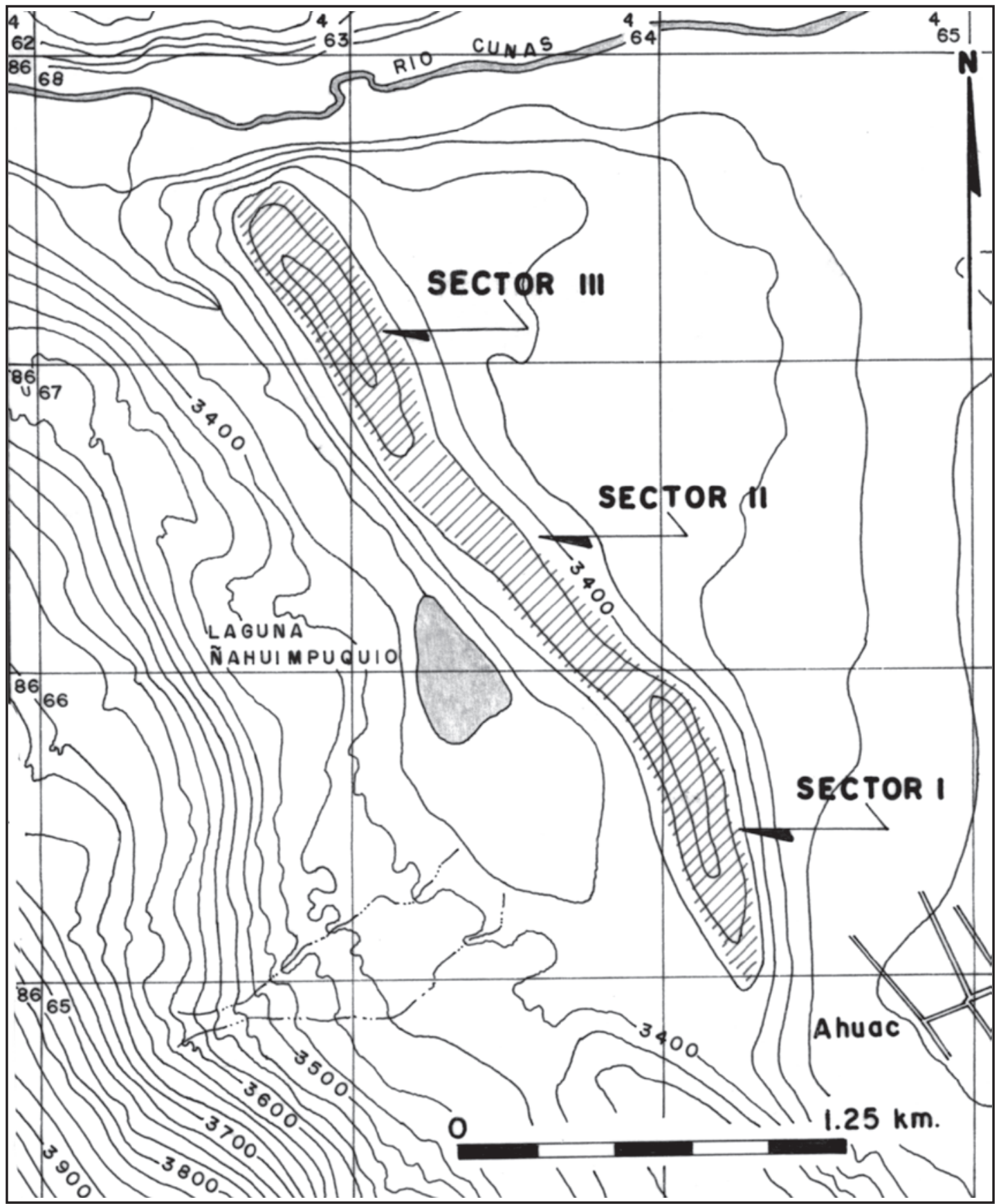

Figura 4. Sectorización propuesta para el asentamiento de Arhuaturo. 
las parcialidades de Hananhuanca, Hatun Xauxa y tiempo después también de Lurinhuanca (Hurtado y Solier 2003). Hacia estos años casi todas las tierras alrededor del sitio de Arhuaturo pertenecían a este linaje, aunque se estaban sosteniendo una serie de litigios y pleitos judiciales entre sus miembros y el Común de Indios de Chupaca, los cuales aparentemente quedaron sin sentencia final (Samaniego 1980).

Luego de la crisis de la agricultura en la región y del ocaso de la clase noble indígena que se generalizó en los Andes Centrales hacia finales del siglo XVIII, el curacazgo de la parcialidad de Hananhuanca quedó vacante y estas antiguas propiedades de los Apoalaya quedaron finalmente en manos de arrendatarios y familias locales, la mayoría de las cuales se agruparon a inicios del siglo XIX para formar la aldea de Ahuac (Samaniego 1980).?

\section{El asentamiento prehispánico de Arhuaturo}

De acuerdo a la configuración natural del terreno y la disposición de las evidencias arquitectónicas, el sitio de Arhuaturo puede subdividirse en tres sectores principales, ${ }^{8}$ los que describimos a continuación (ver Figura 4).

\section{Sector I}

Comprende la sección meridional del sitio, hacia el paraje denominado Lliullaca. Browman (1970) lo registró de forma separada como los sitios PJuM 639, PJuM 640 y PJuM 641 que corresponderían a los períodos Intermedio Tardío y Horizonte Tardío.

Esta parte de la colina alcanza una altitud de casi 3.460 msnm y en gran medida ha sido habilitada para la agricultura, razón por la que muchas estructuras arqueológicas fueron derruidas en el pasado y de las cuales hoy sólo quedan rumas dispersas de piedras. Las evidencias arquitectónicas mejor preservadas consisten en un conjunto de diecisiete edificios dispuestos en hilera que siguen un acimut aproximado de 300 Ÿ(Figura 5). La estructura ubicada en el extremo norte es circular y cuenta con un diámetro de cuatro metros, aunque su estado de conservación no es muy bueno. Las dieciséis edificaciones restantes presentan planta rectangular, con dimensiones internas promedio de 5.6 metros de largo por 3.2 de ancho, siendo sus esquinas internas curvas a diferencia de las externas que son rectas y que forman ángulos de 90 ŸEn la cara oriental de estos edificios, que en algunos casos sobrepasan los 3.7

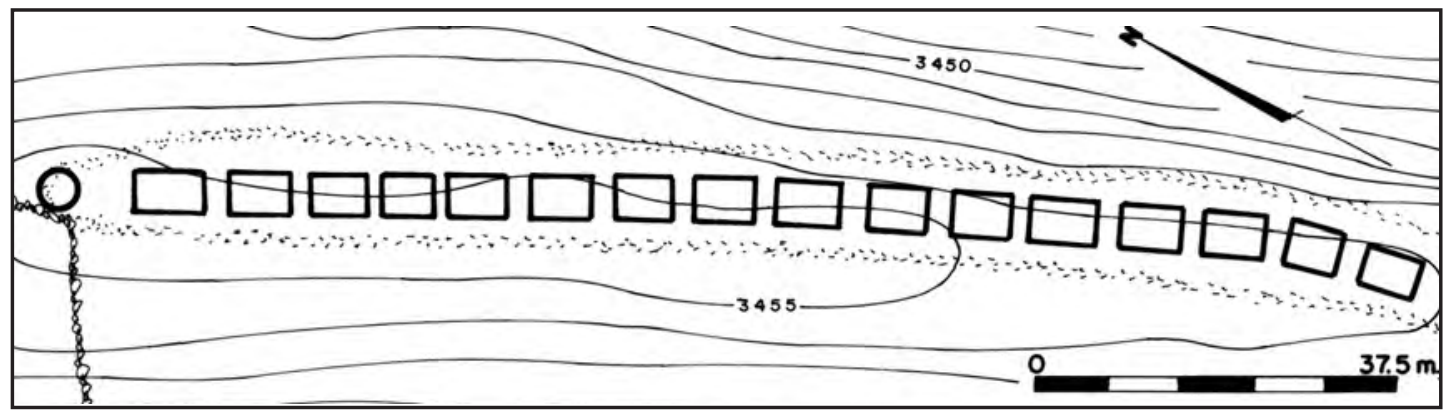

Figura 5. Estructuras en hilera (colcas) en el Sector I de Arhuaturo.

${ }^{7}$ La historia de la zona de Ahuac ha sido estudiada con más profundidad por Cerrón (1956) aunque también encontramos datos adicionales en Castro (1992) y Ordaya (1957). Sobre el punto, muchos documentos han sido reportados en el importantísimo trabajo de Dunbar Temple (1942) en los cuales se señalan los juicios y disputas llevados a cabo en la segunda mitad del siglo XVIII entre el común de indios de Chupaca y la familia Dávila-Astucuri, descendiente de los Apoalaya, por la propiedad sobre las tierras Aguac, Quisguar-puquio, Amaro-cancha, Anta, entre otras.

${ }^{8}$ Esta sectorización fue propuesta antes por el Instituto Nacional de Cultura de Junín y su uso se generalizó a fines de la década de 1990. 
metros de altura, también se observan restos de vanos de ventilación de forma ligeramente trapezoidal, preparados generalmente a un metro o metro y medio sobre el nivel del suelo. En su totalidad los muros presentan $70 \mathrm{~cm}$ de espesor, están ligeramente inclinados hacia el interior y se encuentran constituidos por una doble hilera de piedras asentadas en argamasa de barro. El espacio entre estructura y estructura es de 1.5 metros en promedio, las mismas que presentan además una especie de clavos de piedra en el paramento externo de los muros del ladosur.

\section{Sector II}

Se localiza en la parte central del sitio, en el paraje conocido como Huinso, a una altitud promedio de $3.430 \mathrm{msnm}$. Este sector comprende los sitios PJuM 642 y PJuM 643 del registro de Browman, pertenecientes asimismo a los períodos Intermedio Tardío y Horizonte Tardío (Browman 1970).

Aquí también la expansión de los campos de cultivo ha ocasionado la destrucción de varias construcciones prehispánicas, en su mayoría edificios circulares, quedando en pie y en un regular estado de conservación principalmente dos estructuras de planta rectangular que fueron también levantadas con muros de piedra y barro de $70 \mathrm{~cm}$ de espesor promedio y que a veces alcanzan los 2.7 metros de altura (Figura 6). La mayor de ellas mide por su interior 27.3 metros de largo por 5.7 de ancho y presenta un acimut de $64 \ddot{Y}$ además de al menos dos o tres vanos de acceso en la cara que mira al sur, hacia un espacio abierto hoy convertido en campo de cultivo donde se halla el edificio menor que mide 6.5 metros de largo por 4.4 de ancho (medidas internas) y que presenta un acimut de 60 ŸLos muros aquí también tienen $70 \mathrm{~cm}$ en promedio de espesor, aunque en este caso todavía se pueden observar los restos de un revoque de barro de color rosáceo en su paramento interno.

\section{Sector III}

Abarca la parte norte y más elevada del sitio, hacia el paraje denominado Shrumarsh, a casi $3.470 \mathrm{msnm}$. En el registro de Browman (1970) este sector se consigna como los sitios PJuM 644 y PJuM 645 que datarían del Intermedio Tardío y Horizonte Tardío.

La actividad agrícola también ha afectado diversas estructuras arqueológicas, aunque en menor intensidad que en los otros dos sectores, lográndose observar aún en pie dos conjuntos arquitectónicos principales en regular estado de conservación (Figura 7). El primero está compuesto por ocho edificios rectangulares y cuatro circulares, todos dispuestos en hilera, separados entre sí por un espacio de 1.5 metros en promedio. Las construcciones rectangulares presentan cinco metros de largo por 2.8 de ancho (medidas internas) y exhiben muros de piedra y barro de

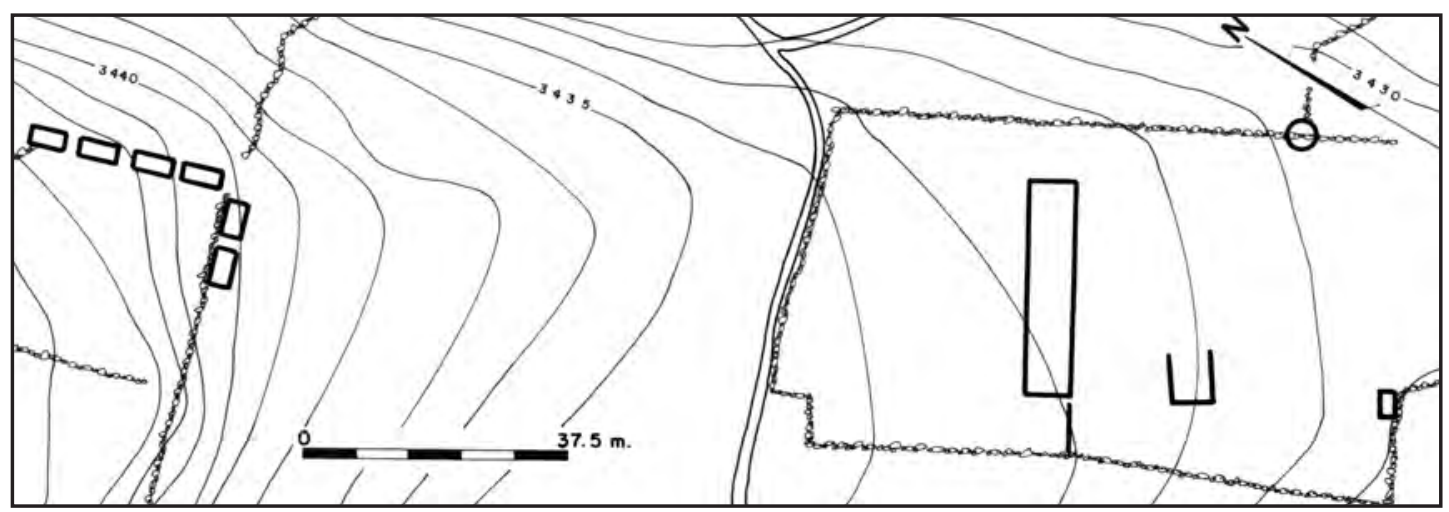

Figura 6. Edificios estatales Inca en el Sector II de Arhuaturo. 


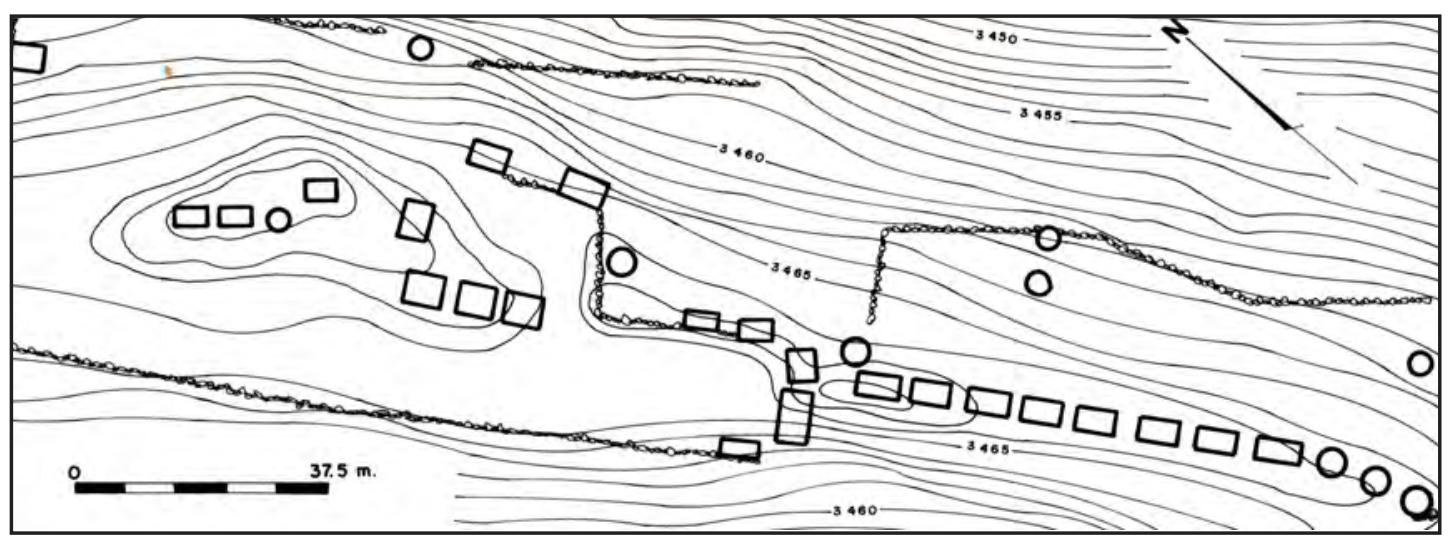

Figura 7. Estructuras en hilera (colcas) y edificios de posible función residencial en el Sector III de Arhuaturo.

$70 \mathrm{~cm}$ de espesor, ligeramente inclinados hacia el interior, con alturas que alcanzan los 3.8 metros en las secciones mejor conservadas, aunque no quedan restos de vano alguno. Además se observan algunos clavos de piedra en el paramento externo de los muros del lado norte de estas edificaciones. El segundo conjunto se halla constituido por más de catorce construcciones, la mayoría de planta rectangular, localizadas al norte de los edificios dispuestos en hilera. Las estructuras, de 4.6 metros de largo y 2.6 de ancho en promedio, se organizan alrededor de espacios abiertos o patios, hacia donde precisamente se orientan sus vanos de ingreso, los mismos que son trapezoidales y que presentan hacia su base $80 \mathrm{~cm}$ de ancho. Los muros de estos edificios, de $70 \mathrm{~cm}$ de espesor y levantados asimismo con piedra y barro, también presentan una ligera inclinación hacia el interior, con alturas que llegan a los 2.5 metros. Una de las estructuras conserva en su vano de acceso un umbral de $20 \mathrm{~cm}$ de altura sobre el nivel actual del suelo.

Es importante recalcar que en cada uno de los tres sectores descritos existen todavía los ras prehispánicas, tanto circulares como rectangulares, que fueron afectadas seriamente por los agricultores modernos en el afán de ampliar sus campos de cultivo por lo cual se ha calculado la extensión de todo el conjunto en unas 40 hectáreas, cifra que parece aproximarse más a la realidad. A esto debemos agregar que cada sector cuenta con un camino antiguo de acceso que permite un traslado fácil y rápido desde del conjunto de Arhuaturo hacia las tierras agrícolas de Auyán y Anta situadas al oriente, así como también hacia la laguna de Ñahuimpuquio localizada al oeste."

\section{Materiales asociados}

A lo largo del sitio se observa una significativa cantidad de cerámica y líticos en superficie, con una mayor densidad hacia el Sector II. En líneas generales gran parte del material alfarero corresponde al tipo Mantaro Base Roja (Lumbreras 1957; Matos 1959) que también ha sido denominado Arhuaturo (Browman 1970) o Alfarería con Temperante de Andesita (Costin 2001). ${ }^{10}$ Las formas más comunes son cuencos y principalmente jarras con decoración pintada y

${ }^{9}$ La recopilación de gran parte de la información aquí presentada se hizo posible gracias al apoyo de Hilarión Guzmán, profundo conocedor de los monumentos arqueológicos de esta parte del valle del Mantaro.

${ }^{10}$ De acuerdo a Costin (2001: 209) la cerámica Mantaro Base Roja vendría a ser en sí la variante engobada del tipo Alfarería con Temperante de Andesita. Basándonos en las evidencias disponibles, su centro 
aplicada. En cantidades mucho menores también se observan fragmentos pertenecientes a otros tipos de la clasificación de Costin (1986, 1986-87) como Base Clara, Engobe Crema y Wanka Rojo entre otros, que representan en mayor número cuencos y algunas ollas.

La alfarería Inca, más abundante también en el Sector II, puede ser clasificada en términos generales en dos grupos principales, Inca provincial e Inca local. ${ }^{11}$ El primero engloba a piezas elaboradas provincialmente en el estilo Cusco y que presentan cierto acabado fino, a diferencia de la cerámica Inca local que es más tosca (D'Altroy 2001b). Las formas representadas en mayor cantidad son platos y principalmente jarras o aríbalos.

Además de cerámica también hemos registrado una significativa cantidad de artefactos de molienda como fragmentos de batanes, morteros y manos de moler, la mayoría elaborados en un tipo de piedra de origen ígneo intrusivo que es llamada por los lugareños alaymosca, materia prima similar a otra con la que se fabricó una especie de azadas o hachuelas de mano que son bastante comunes en los sitios tardíos del valle del Mantaro. ${ }^{12}$ Finalmente también se han observado torteros elaborados a partir de fragmentos de cerámica aunque de distribución muy dispersa a lo largo del sitio.

\section{Discusión}

\section{Problemas cronológicos}

Todos los materiales registrados a nivel de superficie en el sitio de Arhuaturo son indudablemente tardíos al igual que la arquitectura, aunque la carencia de datos procedentes de excavaciones no nos permite por el momento especificar la ubicación cronológica precisa del conjunto. Ello se debe a que en el bajo Cunas, al igual que en casi todo el valle del Mantaro: 1) se produjo durante el Horizonte Tardío una aparente continuidad en la producción de ciertos tipos alfareros locales como Mantaro Base Clara y Base Roja cuyos orígenes se remontan a los tiempos previos del Intermedio Tardío; y 2) la cerámica Inca tiene una presencia marcada en la mayoría de las colecciones procedentes de los asentamientos locales.

Estos problemas, ya señalados antes por Earle et al. (1988), se complican aún más debido a que bajo el régimen Inca se formaron en la región varios asentamientos locales que mantuvieron las características básicas de la arquitectura local (D'Altroy 1992), dificultando en gran medida la ubicación cronológica exacta de muchísimos sitios a partir únicamente de un reconocimiento de superficie.

En Arhuaturo podemos apreciar una significativa cantidad de edificios circulares de piedra y barro levantados sobre terrazas artificiales y organizados alrededor de pequeños patios que son exclusivos de la tradición arquitectónica local (DeMarrais 2001). Ello, sumado a su ubicación sobre una colina y a la presencia de alfarería Mantaro Base Roja y Clara, deja abierta la posibilidad de su pertenencia al Intermedio Tardío, aunque para las regiones del bajo Cunas y el sur del valle del Mantaro aún no se han logrado establecer diferencias mayores dentro de este período. Al respecto el único aporte de trascendencia es el de Browman (1970) quien subdividió el Intermedio Tardío en dos fases, Matapuquio (1050-1250 d.C.) y Arhuaturo (1250-1470 d.C.), que a grandes rasgos se correlacionarían con las fases Wanka I (1000-1350

de producción se estaría localizando hacia el sur del valle del Mantaro (C. Hastings, comunic. pers. 1999). A ello debemos agregar que su presencia es abundante en gran parte del norte del departamento de Huancavelica (vg. Lavallée y Julien 1983; Perales 2000).

${ }^{11}$ Esta clasificación se basa en los criterios de D'Altroy (2001b). Ideas complementarias fueron tomadas de Matos (1999).

${ }^{12}$ Según Hastorf et al. (1989) estos artefactos habrían servido precisamente como azadones para roturar el suelo en las labores agrícolas y su producción habríase iniciado a partir del Intermedio Temprano. 
d.C.) y Wanka II (1350-1450 d.C.) establecidas para la región de Jauja por el proyecto Alto Mantaro (D'Altroy 1992, 2001a; Earle et al. 1987). Sin embargo Browman (1970) consigna a los diferentes sitios que conforman el conjunto de Arhuaturo como pertenecientes tanto a la fase Matapuquio como Arhuaturo. ${ }^{13}$

En conclusión, aunque muchas de las evidencias de superficie datan claramente del Horizonte Tardío (fase Arhuaturo-Inca de Browman, 1970), es muy probable que el asentamiento de Arhuaturo tenga sus orígenes en tiempos del Intermedio Tardío, hecho que deberá ser corroborado con excavaciones sistemáticas en el sitio.

\section{Las ocupaciones locales}

Las evidencias arqueológicas presentadas en esta oportunidad señalan claramente una ocupación Inca intensiva en Arhuaturo. Sin embargo es importante plantear algunas consideraciones previas en torno a las ocupaciones locales.

La significativa presencia de edificios de planta circular organizados alrededor de espacios abiertos o patios, de manera similar a lo observado en distintos asentamientos locales tardíos de la sierra central del Perú (vg. Bonnier 1997; Earle et al. 1987, Lavallée y Julien 1983) confirmaría el carácter residencial de Arhuaturo, toda vez que estos "grupos de patio" o "unidades alveolares" constituyeron las células arquitectónicas básicas en estos sitios, cuya función fue la de albergar a familias o unidades domésticas (DeMarrais 2001). El avanzado estado de destrucción de muchos de estos edificios en Arhuaturo dificulta una aproximación cercana al número de conjuntos residenciales con que podría haber contado originalmente el asentamiento, muchas de las cuales habríanse extendido también hacia las laderas de la colina, a diferencia de los edificios rectangulares asocia- dos a material alfarero Inca que se hallan concentrados principalmente en la cima.

Debido también al mal estado de conservación de estas construcciones circulares resulta difícil por el momento obtener una idea clara acerca de la organización interna original del asentamiento, la misma que habría sido además alterada con la construcción de los edificios de inspiración Inca que se observan en cada uno de los tres sectores.

Pese a que carecemos de evidencias de una plaza central como sí ocurre en los asentamientos tardíos de Jauja (Bonnier 1997; DeMarrais 2001; Earle et al. 1987) por el momento estamos postulando que ella pudo existir en el Sector II donde precisamente se hallan los edificios Inca de mayor envergadura e importancia sociopolítica (Figura 6).

Otro aspecto interesante es la aparente ausencia de elementos defensivos en Arhuaturo pues hasta el momento no hemos registrado muros perimétricos o zanjas en los bordes del sitio, a diferencia de los grandes asentamientos locales que se encuentran en Jauja (DeMarrais 2001; Earle et al. 1987) e inclusive en algunas partes altas del sur del valle del Mantaro (Perales y Rodríguez 2003).

Por último, la notable recurrencia de jarras y cuencos del tipo Mantaro Base Roja sugieren el desarrollo de actividades en las que la producción y consumo de alimentos y bebidas a cierta escala mayor fue parte importante de la vida de la población local. Al respecto, los datos del proyecto Alto Mantaro señalan que durante el Intermedio Tardío la alfarería de este tipo era un bien de demanda significativa al que las familias de élite tenían un mejor acceso (Costin 2001). Estos indicios podrían indicar que al menos una porción de los habitantes de Arhuaturo ostentaba en tiempos previos a la conquista Inca cierto nivel de status y prestigio en el contexto sociopolítico local, posiciones que podrían haber sido

\footnotetext{
${ }^{13}$ Creemos que ello puede deberse a que según Browman (1970) la fase Matapuquio se caracterizaba por la producción de cerámica Mantaro Base Clara o Matapuquio en su secuencia alfarera regional, en tanto que ocurría lo propio con la cerámica Arhuaturo o Mantaro Base Roja durante la fase Arhuaturo. Como hemos visto, ambos tipos alfareros se hallan presentes en el sitio que estamos reportando.
} 
renovadas y reforzadas mediante la organización de ceremonias y festividades públicas.

En base a lo expresado, resulta claro que Arhuaturo constituyó un asentamiento local de considerable importancia que, de confirmarse su ubicación cronológica desde el Intermedio Tardío, habría encabezado por sus dimensiones la jerarquía local de asentamientos en el bajo Cunas en este periodo al lado del sitio de Huaturi en Huáchac (Perales 2002). Ello estaría además confirmado por la presencia de cerámica de manufactura local que servía como marcador de posición y rango.

\section{Naturaleza de la ocupación Inca en Arhuaturo}

Por sus características formales las estructuras levantadas en los sectores I y III habrían sido depósitos estatales o colcas. ${ }^{14}$ Sin embargo en el Sector III el conjunto de edificios rectangulares ubicado al norte de los depósitos habría formado parte de una especie de barrio residencial debido a que las estructuras en su totalidad se organizan en torno a patios centrales, siguiendo quizás el modelo de las típicas canchas incaicas. Por su parte, los edificios rectangulares del Sector II que aquí hemos presentado se vinculan de forma más evidente con los patrones arquitectónicos Inca, especialmente la estructura mayor que vendría a ser una variedad de callanca cuyos accesos miraban hacia una espacio abierto adyacente hacia el lado sur donde también se encontraban otras construcciones de clara inspiración cuzqueña (Gasparini y Margolies 1977; Hyslop 1990; Kendall 1976).

Como ya vimos, todas estas construcciones, pese a que eventualmente alternan con estructuras circulares, presentan claramente cerámica Inca asociada.
La edificación de este tipo de infraestructura estatal dentro del asentamiento de Arhuaturo revela vínculos cercanos entre la población nativa y el estado Inca, más aún si consideramos la potencial importancia de este sitio en el panorama sociopolítico local como sede de algunos linajes de élite que habrían tenido acceso a una significativa cantidad de mano de obra y de recursos pues se halla emplazado en una zona de alta concentración demográfica y de gran potencial agropecuario; en un punto estratégico para acceder y controlar la sección media y alta de la cuenca del río Cunas. Estas relaciones establecidas entre los Inca y las elites de Arhuaturo debieron desarrollarse y exteriorizarse mediante ceremonias y festividades auspiciadas por el Estado en el marco de sus principios de reciprocidad y hospitalidad ritual (Morris 1998) que quizás tuvieron como escenario a la callanca y edificios asociados en el Sector II.

Para la arqueología será muy difícil saber si la administración Inca del asentamiento y su entorno estuvo a cargo de funcionarios cusqueños, sin embargo es evidente que aún cuándo ése hubiera sido el caso, de igual forma las élites o algunos linajes del lugar se habrían incorporado de modo alguno a las labores burocráticas en beneficio del estado. Al menos así lo sugieren las posibles viviendas de inspiración Inca que se observan en el Sector III de Arhuaturo y la amplia distribución de cerámica Inca en todo el asentamiento. ${ }^{15}$

En síntesis, la intensidad de la ocupación Inca en Arhuaturo debió corresponder en gran medida al status sociopolítico e importancia económica de este asentamiento con la finalidad de consolidar el régimen del Tahuantinsuyu en la región, incorporando al menos a una parte de la nobleza nativa dentro de la esfera estatal Inca a

${ }^{14}$ Aparte de su disposición en hilera y ubicación en partes elevadas, las evidencias para postular el carácter de depósitos estatales de estas construcciones son: carencia de vanos de ingreso, presencia de vanos de ventilación y presencia de alfarería Inca asociada. Para mayor discusión sobre el tema ver Morris y Thompson (1985) y D'Altroy $(1981,1992)$ por ejemplo.

${ }^{15}$ Evidencias similares sobre la incorporación de las élites locales en la esfera estatal Inca han sido reportadas antes por D'Altroy (1992) en Jauja, Grosboll (1993) en Huánuco, Schreiber (1993) en el sur de Ayacucho, Perales (2004a) en el valle de Ricrán al norte de Jauja, entre otros. 
fin de garantizar un acceso más seguro a la mano de obra y recursos de la localidad, así como para establecer vínculos políticos fuertes con los grupos de poder local aprovechando el ambiente de fragmentación política heredada en la zona desde tiempos del Intermedio Tardío. Como veremos a continuación, entre aquellos linajes en competencia habrían estado los Apoalaya.

\section{Arhuaturo en el contexto regional}

De acuerdo a las investigaciones del proyecto Alto Mantaro realizadas en Jauja, extremo norte del valle del Mantaro, sabemos que durante el Horizonte Tardío se produjo allí un traslado masivo de la población local desde los grandes asentamientos nucleados ubicados sobre cumbres de cerros elevados hacia colinas bajas y estribaciones laterales del valle, ocasionando la formación de un sinnúmero de aldeas pequeñas y dispersas que contaban con un mejor acceso a las tierras de cultivo (D'Altroy 1992; Hastorf 2001; LeBlanc 1981). Ello implicó el traslado de los núcleos tradicionales del poder político desde los centros regionales de Tunanmarca y Hatunmarca hacia Hatun Xauxa, la capital Inca del valle del Mantaro. En este contexto ciertos sectores de la elite local fueron incorporados dentro del aparato de gobierno del Tahuantinsuyu con la finalidad de establecer un mejor control sobre la mano de obra y la producción local, proceso que además provocó algunos cambios en la naturaleza y magnitud de ciertas actividades desarrolladas en los contextos domésticos Xauxa (D'Altroy 1992, 2001a).

Por el momento esta situación no puede ser generalizada sobre el resto del valle del Mantaro, debido principalmente a la falta de investigaciones sistemáticas. Sin embargo, en base a algunos reconocimientos arqueológicos que hemos iniciado en el bajo Cunas podemos indicar que en esta zona los asentamientos del Intermedio Tardío fueron en su mayoría poco extensos y dispersos, localizados sobre colinas o estribaciones montañosas que encierran al valle del Mantaro por el oeste. Además, la mayoría de estos sitios presenta cerámica Inca en superficie, tal como ya lo indicara Browman (1970), aunque no siempre modificaciones en su organización arquitectónica interna.

La jerarquía local de asentamientos estuvo encabezada, como ya se indicó, por los sitios de Arhuaturo y Huaturi, donde se aprecian significativas cantidades de cerámica Mantaro Base Roja en las colecciones de superficie. Al parecer este patrón de asentamiento no sufrió cambios drásticos durante el Horizonte Tardío (Browman 1970) y muchos de los sitios locales referidos exhiben cerámica Inca e incorporan nuevos edificios que alteran su organización interna previa como ocurre en Arhuaturo, Coto CotoCapillayoc, Callpish y Torrehuata. ${ }^{16}$ Casi paralelamente se levantaron centros de almacenaje estatal en los sitios de Ulla Ulo, Huaturi, Quillayoc y Tanquish Tanquish, además de instalaciones especiales en el sitio de Acllahuasi, el cual estuvo ligado a un camino Inca que, partiendo del conjunto arqueológico de Patan Coto, cruzaba las pampas de Sicaya (Escobar 1973) y ascendía por la localidad de Tinyari hacia la cordillera de Ninanya, a la cual coronaba en el paso de Incacruz, para finalmente descender hacia las altiplanicies de Laive-Ingahuasi y dirigirse hacia la costa sur-central (Perales 2004b). ${ }^{17}$

Como se puede apreciar, las evidencias arqueológicas sugieren que durante los años del dominio Inca la sección inferior del valle del Cunas no sufrió fuertes alteraciones en la distribución de su población y que por el contrario, los

${ }^{16}$ En el sitio de Coto Coto-Capillayoc, localizado en los límites entre los distritos de Manzanares y Chambará, se levanta otra posible callanca de características y dimensiones similares a la de Arhuaturo (Perales 2002).

${ }^{17}$ El sitio de Patancoto se localiza en la margen izquierda del valle del Mantaro, a ocho kilómetros al norte de Huancayo y por allí pasaba el camino troncal de la sierra que se dirigía del Cusco a Quito. El cami 
asentamientos más importantes como Arhuaturo y Huaturi fueron reocupados de modo un tanto intensivo, convirtiéndose posiblemente en los escenarios donde ciertos segmentos de la elite local adherida al aparato gubernamental Inca auspiciaron o desarrollaron diferentes actividades con las que el estado Inca extendía sus relaciones de reciprocidad y hospitalidad ritual con la población local en retribución por los tributosy servicios prestados por ésta.

Tomando en cuenta la documentación etnohistórica podemos pensar que la clase noble residente en Arhuaturo habría ocupado una posición importante en la estructura administrativa estatal de la zona, especialmente si consideramos que el linaje de los Alaca tenía vínculos familiares directos con los Apoalaya, curacas de la parcialidad de Hananhuanca (Cieza, 1946 [1553]; Pachacuti Yamqui 1995 [1613]), con quienes los Inca mantuvieron relaciones bastante estrechas, principalmente desde tiempos de Huayna Cápac (Perales 2002).

De otro lado debemos indicar que la producción textil habría sido una actividad fundamental en todo este proceso de consolidación del dominio Inca en la región del bajo Cunas. El camino estatal antes mencionado une de modo estratégico a las planicies de Yanacancha y LaiveIngahuasi, ricas en agua y buenos pastos, con la sección más densamente poblada de esta parte del valle del Mantaro, el bajo Cunas, donde se encontraba un posible centro estatal Inca de producción textil: el sitio de Acllahuasi, muy cercano a Arhuaturo (Castro 1992; Perales 2002). ${ }^{18}$ Durante los primeros tiempos de la Colonia persistió la importancia de este eje eco- nómico y continuaron siendo famosas las haciendas ganaderas de Laive-Ingahuasi y Yanacancha, cuya producción lanar controlada por los Apoalaya se empleaba en la manufactura de textiles en el chorrillo de Tacana, ubicado a escasos dos kilómetros al sur-este de Arhuaturo (Cerrón 1956). Todavía en el siglo XVIII el monopolio de la producción textil en la zona estaba en manos de este mismolinaje(Hurtado 2000).

\section{Comentarios finales}

No obstante la mayor parte de ideas esbozadas en esta ocasión se basan en datos de carácter superficial, consideramos que pueden contribuir en la definición de una agenda de investigación sobre el carácter de la ocupación Inca en la sección meridional del valle del Mantaro, hacia el curso inferior del río Cunas.

La naturaleza de los vestigios materiales Inca procedentes del asentamiento de Arhuaturo que hemos reportado en esta ocasión es bastante diferente de la de aquellas observadas hacia Jauja y definitivamente sugieren estrategias muy distintas de conquista y consolidación del poder Inca aunque seguramente relacionadas de forma estrecha entre sí. Por ello un estudio sobre el carácter de la ocupación Inca en el bajo Cunas ayudará a comprender en alguna manera: 1) la gran versatilidad de las estrategias empleadas por los Inca en la anexión de nuevos territorios a su imperio; 2) la naturaleza misma del estado Inca y los cambios que experimentó a través de su corta existencia; y 3) las formas en que las distintas élites conquistadas intentaron tomar ventaja de la nueva coyuntura política al ser incorporadas al Tahuantinsuyau y cómo este juego alteró el

no que estamos mencionando en esta ocasión es denominado explícitamente como "el camino real del valle de Jauxa [sic] que va al de Chincha" en varios documentos de inicios del siglo XVIII recuperados por Aquilino Castro y que se refieren a la tasación de bienes y delimitación de las haciendas ganaderas de Laive-Ingahuasi y Yanacancha, pertenecientes a las hermanas Teresa y Petrona Apoalaya, hijas de don Carlos Apoalaya, curaca gobernador de la parcialidad de Hananhuanca en aquel entonces.

${ }^{18}$ Lamentablemente ahora casi no queda nada del sitio de Acllahuasi a nivel de superficie. Las estructuras rectangulares que allí existían fueron derruidas para vender las piedras para la construcción de viviendas modernas en Huancayo durante la década de 1950 (Crisolfo Perales, comunic. pers. 2001). 
panorama sociopolítico local.

Partiendo de las evidencias del sitio de Arhuaturo, podemos postular que en el bajo Cunas al menos una parte importante de la elite local fue incorporada al aparato de gobierno Inca con la finalidad de garantizar el acceso eficiente y seguro a recursos y mano de obra, aprovechando seguramente los conflictos políticos preexistentes a nivel local. Muchos de estos linajes adherentes debieron sacar ventaja de esta situación ganando nuevas posiciones de autoridad y prestigio ante los ojos de su población, aspecto que habría sido exteriorizado con el despliegue de actividades rituales, festivas y administrativas en las que manipularon símbolos oficiales del régimen como viviendas de inspiración Inca, cerámica y tejidos, todo ello con la venia del Estado. De este modo segmentos de la élite local como los Alaca de Arhuaturo afianzaron su status y poder político gracias a sus vínculos con linajes cercanos a los Inca pero foráneos a nivel de su comunidad inmediata como los Apoalaya de Sapallanga, hechos que formaron parte de un proceso de complejización en la organización sociopolítica de la zona incentivada por su incorporación al Tahuantinsuyu.

\section{Agradecimientos}

Nuestros reconocimientos arqueológicos a nivel de superficie en el sitio de Arhuaturo fueron financiados por la Municipalidad Provincial de Chupaca entre los años 1999 y 2002 y contaron con la autorización del Instituto Nacional de Cultura a través de su dirección departamental de Junín, donde también tuvimos acceso al levantamiento topográfico sobre el que se basan algunos de los planos presentados en esta ocasión, de lo cual quedamos profundamente agradecidos. Asimismo, queremos expresar nuestra gratitud a Hilarión Guzmán, quien nos proporcionó abundante información sobre la arqueología del distrito de Ahuac, y a Juan Mogrovejo, por habernos facilitado una copia del padrón del aillo Carvaturco referido en este trabajo. Finalmente también deseamos agradecer a José Pino, Brener Meza, Aquilino Castro, Armando Chipana, y especialmente a Manuel Perales Vílchez y Doris Munguía Torres, por su constante estímulo y apoyo moral y material.

\section{Bibliografía}

Bonnier, E.

1997 "Morfología del espacio aldeano y su expresión cultural en los Andes Centrales", en Archaelogica Peruana 2, E. Bonnier y H. Bischof (Eds.), pp. 2841. Sociedad Arqueológica PeruanoAlemana/Reiss-Museum Mannheim.

Browman, D.

1970 Early Peruvian Peasants: The Culture History of a Central Highlands Valley. Ph. D. Dissertation, Departament of Anthropology, Harvard University, Cambridge.

Castro, A.

1992 Hanan Huanca. Lima: Asociación Editorial Stella.

Cerron, $\mathrm{S}$.

1956 Breve historia de Ahuac en la provincia de Huancayo. Huancayo.

Cieza de León, $\mathrm{P}$.

1946 [1533] "La Crónica General del Perú”, en Crónicas de la Conquista del Perú, J. De Riverend (Ed.), pp. 125-497. México: Editorial Nueva España.

Costin, C.

1986 From Chiefdom to Empire State: Ceramic Economy Among the Prehispanic Wanka of Highland Peru. Ph. D. Dissertation, University of California at Los Angeles, Los Angeles.

1986-87 “Cerámica prehispánica tardía del valle de Yanamarca, Junín". Revista del Museo Nacional, 48: 195-211.

2001 Production and exchange of ceramics. En Empire and domestic economy, $\mathrm{T}$. 
242. Kluwer Academic / Plenum Publishers, New York.

D'Altroy, T.

1981 "Empire growth and consolidation: the Xauxa region of Peru under the Incas". Doctoral Dissertation, Department of Anthropology, University of California at Los Angeles, Los Angeles.

1992 Provincial Power in the Inka Empire. Smithsonian Institution Press, Washington and London.

1994 "Factions and political development in the central Andes", en E. Brumfiel y J. Fox (eds.). Factional Competition and Political Development in the New World. pp. 171-187. Cambridge University Press, Cambridge.

2001a "The cultural setting”, en T. D'Altroy y C. Hastorf (eds.). Empire and domestic economy. pp. 27-53. New York: Kluwer Academic/Plenum Publishers.

$2001 b$ "State goods in the domestic economy: the Inka ceramic assemblage", en T. D'Altroy y C. Hastorf (eds.). Empire and domestic economy. pp. 243-264. New York: Kluwer Academic/Plenum Publishers.

De Marrais, E.

2001 "The architecture and organization of Xauxa settlements", en T. D'Altroy y C. Hastorf (eds.). Empire and Domestic Economy. pp. 115-153. New York: Kluwer Academic / Plenum Publishers.

Dunbar Temple, E.

1942 "Los Caciques Apoalaya”. Revista del Museo Nacional 11: 147-178.

Earle, T.; T. D'Altroy; C. Hastorf; C. Scott; C. Costin; G. Russell y E. Sandefur

1987 Archaeological Field Research in the Upper Mantaro Valley, Peru: 1982-1983. Investigations of Inka Expansion and Exchange. Monograph 28. Los Angeles: Institute of Archaeology, University of California at Los Angeles.
Earle, T.; T. D'Altroy; C. Scott; C. Hastorf y T. Levine

1988 "Sobre la penetración inca en el valle del Mantaro". Boletín de Lima 59: 39-50.

Escobar, G.

1973 Sicaya. Cambios culturales en una comunidad mestiza andina. Lima: Instituto de Estudios Peruanos.

Espinoza, W.

1971 "Los Huancas, aliados de la conquista". Anales Científicos de la Universidad del Centro del Perú 1: 3-407.

1973 "Historia del departamento de Junín", en E. Chipoco (ed.). Enciclopedia Departamental de Junín. Tomo I, pp. 9 395. Huancayo: Editorial San Fernando.

Estete, M.

1946 "[1533] La relación del viaje que hizo el Señor Capitán Hernando Pizarro por mandado del señor gobernador, su hermano, desde el pueblo de Caxamalca a Parcama y de allí a Jauja”, en J. De Riverend (ed.). Crónicas de la Conquista del Perú. pp. 90-108. México: Editorial Nueva España.

Fung, R.

1959 "Informe preliminar de las excavaciones efectuadas en el Abrigo Rocoso NŸ1 de Tschopik", en Actas y Trabajos del II Congreso Nacional de Historia del Perú, tomo I, pp. 253-274. Lima: Centro de Estudios Histórico-Militares del Perú.

Gasparini, G. y L. Margolies

1977 Arquitectura Inka. Caracas: Centro de Investigaciones Históricas y Estéticas, Facultad de Arquitectura y Urbanismo, Universidad Central de Venezuela.

Grosboll, S.

1993 ...And he said in the time of the Ynga, they paid tribute and served the Ynga, en M. Malpass (ed.). Provincial Inca. pp. 44-76. University of Iowa Press, Iowa City. 
Hastorf, C.; T. Earle; H. Wright; L. Lecount; G. Russell y E. Sandefur

1989 Settlement archaeology in the Jauja region of Peru. Evidence from the Early Intermediate Period through the Late Intermediate Period. A Report on the 1986 Field Season. Andean Past 2: 81 129.

Hurtado Ames, C.

2000 "Curacas y Obrajes. Manufactura textil en el valle del Mantaro, Siglo XVIII". Tesis para optar el título de Licenciado en Historia. Lima: Universidad Nacional Mayor de San Marcos.

Hurtado, C. y V. Solier

2003 "Fuentes para la historia colonial de la sierra central del Perú", Huancayo: Universidad Nacional del Centro del Perú.

Hurtado De Mendoza, L.

1982 "Patrones prehispánicos de uso de diversos tipos de piedra en la región del río Cunas, Huancayo". Revista del Museo Nacional 46: 39-53.

Hurtado De Mendoza, L. y C. Chahud

1982 Algunos datos adicionales acerca del sitio Callavallauri (Abrigo Rocoso NŸ1 de Tschopik). Guaman Poma 2: 9-33.

Hyslop, J.

1990 Inka settlement planning, University Texas Press. Austin.

Kaulicke, P.

1994 "Los Orígenes de la Civilización Andina”, en Historia General del Perú, tomo I. Lima: Editorial Brasa.

Kendall, A.

1976 Descripción e inventario de las formas arquitectónicas Inca. Revista del Museo Nacional 42: 13-96.

Lavallée, D. y M. Julien

1983 Asto: curacazgo prehispánico de los Andes Centrales. Lima: Instituto de Estudios Peruanos.
Leblanc, C.

1981 Late Prehispanic Huanca Settlement Patterns in the Yanamarca Valley, Peru. Doctoral Dissertation, Department of Anthropology. University of California at Los Angeles, Los Angeles.

Levine, $\mathrm{T}$.

1985 "Inka Administration in the Central Highlands: A Comparative Study". Doctoral Dissertation, Department of Anthropology, University of California at Los Angeles, Los Angeles.

Lumbreras, L.

1957 "La Cultura Wanka", en Ondas Isabelinas. Organo de la Gran Unidad Escolar Santa Isabel de Huancayo, pp. 15-18. Huancayo.

Matos, R.

1959 "Los Wanka: datos históricos y arqueológicos”. Actas y Trabajos del II Congreso Nacional de Historia del Perú: Epoca Prehispánica, tomo 2, pp. 187-210. Lima: Centro de Estudios Histórico-Militares del Perú.

1999 "La Cerámica Inca". en Los Incas. Arte y Símbolos, Colección Arte y Tesoros del Perú, pp. 109-165. Lima: Banco de Crédito del Perú.

Morris, C.

1998 "Inka strategies of incorporation and governance”, en G. Feinman y J. Marcus (eds.). Archaic States. pp. 293-309. School of American Research, Santa Fe, New Mexico.

Morris, C. y D. Thompson

1985 Huanuco Pampa: an Inca city and its hinterland. Thames and Hudson, London.

Ordaya, T.

1957 "Chupaca". Estudio monográfico, Huancayo.

Pachacuti Yamqui, J.

1995 [1613] Relación de Antigüedades de este 
Reino del Perú. C. Araníbar (ed.). Lima: Fondo de Cultura Económica,

Perales, $\mathrm{M}$.

2000 "Los restos arqueológicos de WillcánMuyupata”, en Pichos, monografía, P. Cerrón, pp. 24-31. Comunidad Campesina de Pichos, Tayacaja.

2002 "Los Apoalaya y la ocupación Inca en la cuenca del Cunas", en P. Cerrón (ed.). Origen y Trayectoria Cultural de Chupaca. pp. 7-17. Chupaca: Municipalidad Provincial de Chupaca, Fondo Editorial.

2004a "Apuntes sobre la presencia Inca en la cuenca alta del río Ricrán, sierra central del Perú". Manuscrito en posesión del autor.

2004b "Sobre el desarrollo de la provincia de Chupaca: esbozo de una propuesta desde la arqueología". Wankam Kanchik 7:02-03.

Perales, M. y A. Rodríguez

2003 "Asentamientos prehispánicos tardíos en la puna de Chongos Bajo (ChupacaJunín)". Unay Runa 6: 55-59.

Pulgar, J.

1967 Geografía del Perú: Las Ocho Regiones

Naturales del Perú. Lima: Universidad Nacional Mayor de San Marcos.

Rodríguez, Z.

1996 Valle del Mantaro I. Geomorfología-
Hidrología. Organización para el desarrollo económico, social y ambiental, Huancayo.

Samaniego, C.

1980 "Campesinado en el valle del Mantaro". Estudios Andinos 16:31-72.

Schreiber, K.

1993 "The Inca occupation of the province of Andamarca Lucanas, Perú”, en M. Malpass (ed.). Provincial Inca. pp. 77116. University of Iowa Press, Iowa City.

Tosi, J.

1960 Zonas de vida natural en el Perú. Lima: Instituto Interamericano de Ciencias Agrícolas de la OEA, Zona Andina, Proyecto 39. Programa de Cooperación Técnica, Boletín NŸb. Vega, A.

1881 [1582] La descripción que se hizo en la provincia de Xauxa por la instrucción de Su Majestad que á la dicha provincia se envió de molde", en Relaciones Geográficas de Indias, tomo I, pp.79-95. Madrid: Ministerio de Fomento del Perú.

Xerez, F.

1968 [1533] Verdadera Relación de la Conquista del Perú y Provincia del Cuzco, llamada Nueva Castilla. Lima: Biblioteca Peruana, tomo I. 